\section{One-year mortality among elderly people after hospitalization due to fall-related fractures: comparison with a control group of matched elderly}

\author{
Mortalidade em um ano de idosos após hospitalização \\ por fratura decorrente de queda: comparação com \\ idosos pareados da população
}

\author{
1 Escola Nacional de Saúde \\ Pública Sergio Arouca, \\ Fundação Oswaldo Cruz, \\ Rio de Janeiro, Brasil. \\ 2 Instituto de Estudos em \\ Saúde Coletiva, Universidade \\ Federal do Rio de Janeiro, \\ Rio de Janeiro, Brasil. \\ Correspondence \\ E. S. F. Coutinho \\ Departamento de \\ Epidemiologia e Métodos \\ Quantitativos em Saúde, \\ Escola Nacional de Saúde \\ Pública Sergio Arouca, \\ Fundação Oswaldo Cruz. \\ Rua Leopoldo Bulhões 1480, \\ Rio de Janeiro, $R J$ \\ 21041-210, Brasil. \\ esfcoutinho@ensp.fiocruz.br
}

\begin{abstract}
Fall-related fractures among the elderly represent an important public health problem. Severe fractures have been related to increased risk of death. In order to investigate the mortality profile of elderly individuals with severe fractures, 250 patients aged 60 years and over, hospitalized due to fall-related fractures and 250 elderly without fractures living in the local community were followed-up for one year. They were matched according to sex, age, time of hospitalization and neighborhood. Deaths were identified using probabilistic linkage of the research dataset and the local mortality registry. The one-year cumulative mortality was $25.2 \%$ in the case of individuals with severe fractures and $4 \%$ for those individuals without. The mortality distribution was not homogeneous across the follow-up period. Twothirds of deaths among the elderly individuals hospitalized due to fracture occurred within the first 3 months, whereas mortality among those individuals without fractures took place later. Heart disease, pneumonia, GI bleeding, sepsis, and pulmonary embolism, diabetes and stroke were important causes of one-year mortality.
\end{abstract}

Bone Fractures; Accidental Falls; Aged; Survival Analysis; Mortality
Evandro Silva Freire Coutinho 1

Katia Vergetti Bloch 2

Claudia Medina Coeli 2

\section{Introduction}

Fall incidents and fall-related fractures among the elderly are an important public health problem due to their personal effects on the patient and the economic burden they impose. About one-third of people aged 65 years and over experience an annual fall, of which $5-10 \%$ suffer a severe fracture 1,2 . Severe fractures, particularly of the hip, represent a public health problem, leading to hospitalization, long-term rehabilitation, reduced quality of life, and high one-year mortality rates 3 .

A systematic review showed that individuals experiencing hip fractures have a considerable excess risk of death compared to control individuals without fractures living in the local community. Furthermore, this increased risk of mortality may persist for several years after the accident 4 . These findings highlight the need for targeted interventions for this high risk group.

The aim of this brief report is to compare the one-year mortality risk of elderly people hospitalized due to fracture after a fall with the risk in a control group without fractures.

\section{Methods}

The data used in the present analysis was obtained from cases and community controls from a case-control study carried out to investigate 
risk factors and the consequences of severe fallrelated fractures among individuals aged 60 years and over. Details of the methods of the original study can be found in other publications 5,6.

The present investigation made use of a cohort design to compare mortality between 250 patients aged 60 years and over hospitalized due to a fall-related fracture and 250 elderly individuals without fracture living in the local community. These groups were matched according to sex, age, time of hospitalization and neighborhood in the original case-control study. Deaths occurring within the period of one year after an index fracture were identified using probabilistic linkage of the study dataset and the local mortality registry using RecLink software ${ }^{7}$. The validity of this procedure was assessed using the method adopted by Coutinho \& Coeli 8 , showing a sensitivity of $86 \%$ and a specificity of $99 \%$.

Cumulative mortality risk was estimated for hospitalized individuals and control individuals after one month, three months and one year. Kaplan-Meier survival mortality estimates were obtained and the statistical significance of the difference between the two groups was calculated using log-rank tests. Causes of death were also investigated.

The statistical analysis was performed using Stata 10.0 (Stat Corp., College Station, USA).

The study was approved by the ethics committee of the National School of Public Health of the Oswaldo Cruz Foundation (Escola Nacional de Saúde Pública Sergio Arouca, Fundação Oswaldo Cruz).

\section{Results}

Women represented $78 \%$ of the sample. Mean age was 75.5 years $(\mathrm{SD}=8.2)$ for hospitalized cases and 75.3 years $(\mathrm{SD}=7.7)$ for control individuals. The most common type of fracture was hip fracture (72\%), followed by arm/forearm fracture (19\%). Eleven cases of fracture $(4.4 \%)$ had more than one bone fractured. Ninety nine per cent of them underwent surgery.

Figure 1 depicts the cumulative mortality curves for the two groups. The one-year cumulative mortality for individuals hospitalized due to fracture was $25.2 \%$ (63 deaths) and $4 \%$ in the control group (10 deaths). However, the distribution of deaths throughout the follow-up period was not homogeneous. The one-month cumulative mortality for the hospitalized elderly was $11.6 \%$, whereas no deaths occurred in the control group during this period. With respect to the three-month period, mortality risks were $16.4 \%$ and $0.8 \%$ for those with and without severe fracture, respectively. It is important to note that 29 of the 63 deaths (46\%) in hospitalized group occurred during the first month after an index fracture, and 41 (65\%) took place within the first three months following the incident.

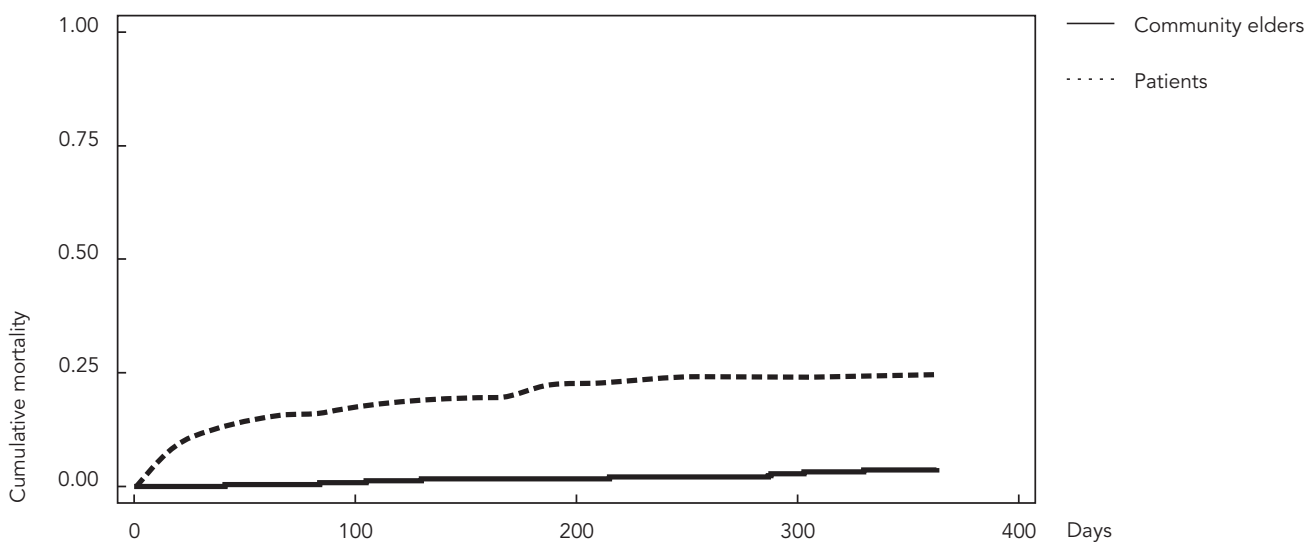

Note: log rank test $p<0.001$. 
With respect to individuals with a severe fracture, cumulative mortality was higher for men than in women: 1.14 (95\%CI: $0.60-2.18$ ) for one month, 1.40 (95\%CI: 0.83-2.35) for three months and 1.42 (95\%CI: $0.90-2.24)$ for one year: however, these differences did not reach statistical significance.

The mortality profile of the cases is presented in Table 1. Pneumonia, heart disease, GI bleeding, sepsis, trauma and procedural complications and pulmonary embolism were responsible for two-thirds of the deaths occurring within the first month after an index fracture. Over the oneyear period, diabetes, heart disease, pneumonia, GI bleeding, sepsis, stroke, pulmonary embolism and respiratory disease accounted for two-thirds of the deaths. Among the 10 deaths in the group without fracture, heart disease was the most common cause.

\section{Discussion}

The risk of death within of period of one-year was about six times greater in individuals from the group admitted to hospital due to a fall-related fracture than in the control group. Although this result is similar to findings reported in two systematic reviews of hip fractures 4,9 , the risk ratio in our investigation was greater than those observed by the majority of studies covered by these reviews.

With respect to the distribution of deaths in the year following the index fracture, our findings are consistent with those reported by other authors. Roche et al. 10 found a mortality risk of $9.6 \%$ during the first 30 days and $33 \%$ after a period of one year, while Panula et al. 11 reported risks of $10.5 \%$ and $27.3 \%$ for the same periods. A review undertaken by Abrahamsem 4 reported that

Table 1

Causes of death of elderly individuals with and without fall-related fractures up to one month after * and one year after the accident.

\begin{tabular}{|c|c|c|c|c|c|c|}
\hline \multirow[t]{3}{*}{ Cause of death } & \multicolumn{4}{|c|}{ With severe fracture } & \multirow{2}{*}{\multicolumn{2}{|c|}{$\begin{array}{c}\text { Without severe fracture } \\
\text { Up to one year after }\end{array}$}} \\
\hline & \multicolumn{2}{|c|}{ Up to one month after } & \multicolumn{2}{|c|}{ Up to one year after } & & \\
\hline & n & $\%$ & $\mathbf{n}$ & $\%$ & $\mathbf{n}$ & $\%$ \\
\hline Pneumonia & 3 & 10.4 & 5 & 7.9 & 2 & 20.0 \\
\hline Heart disease & 4 & 13.8 & 7 & 11.1 & 5 & 50.0 \\
\hline Gl bleeding & 3 & 10.4 & 5 & 7.9 & 0 & 0.0 \\
\hline Sepsis & 4 & 13.8 & 5 & 7.9 & 0 & 0.0 \\
\hline $\begin{array}{l}\text { Complications of } \\
\text { trauma/procedures }\end{array}$ & 3 & 10.4 & 3 & 4.8 & 0 & 0.0 \\
\hline Pulmonary embolism & 3 & 10.4 & 4 & 6.3 & 0 & 0.0 \\
\hline Urinary infection & 1 & 3.5 & 1 & 1.6 & 0 & 0.0 \\
\hline Breast cancer & 1 & 3.5 & 1 & 1.6 & 0 & 0.0 \\
\hline Osteomyelitis & 1 & 3.5 & 1 & 1.6 & 0 & 0.0 \\
\hline Other GI & 1 & 3.5 & 1 & 1.6 & 0 & 0.0 \\
\hline Neoplasia & 1 & 3.5 & 3 & 4.8 & 1 & 10.0 \\
\hline Fall (femur fracture) & 1 & 3.5 & 1 & 1.6 & 0 & 0.0 \\
\hline Spinal trauma & 1 & 3.5 & 1 & 1.6 & 0 & 0.0 \\
\hline Respiratory disease & 0 & 0.0 & 4 & 6.3 & 0 & 0.0 \\
\hline Diabetes & 1 & 3.5 & 7 & 11.1 & 1 & 10.0 \\
\hline Stroke & 0 & 0.0 & 4 & 6.3 & 0 & 0.0 \\
\hline Renal failure & 0 & 0.0 & 2 & 3.2 & 0 & 0.0 \\
\hline Pressure ulcer & 0 & 0.0 & 2 & 3.2 & 0 & 0.0 \\
\hline Gangrene & 0 & 0.0 & 1 & 1.6 & 0 & 0.0 \\
\hline Hepatitis C & 0 & 0.0 & 1 & 1.6 & 0 & 0.0 \\
\hline Parkinson's disease & 0 & 0.0 & 1 & 1.6 & 0 & 0.0 \\
\hline Physical aggression & 0 & 0.0 & 0 & 0.0 & 1 & 10.0 \\
\hline Ill-defined & 1 & 3.5 & 3 & 4.8 & 0 & 0.0 \\
\hline Total & 29 & 100.0 & 63 & 100.0 & 10 & 100.0 \\
\hline
\end{tabular}

* There were no deaths among individuals without fractures up to one month after the accident. 
between one-quarter and one-third of deaths occurred in the first month after the index fracture, and about half took place during the first three months after fracture.

Diabetes, respiratory disease, heart disease, pneumonia, GI bleeding, sepsis, stroke and pulmonary embolism were responsible for the majority of deaths during the one-year follow-up. Of these, the last five were the most important causes of mortality in the first month after the index fracture. According to Roche et al. 10, the most common postoperative complications among patients with hip fractures were chest infection and heart failure. A study by Panula et al. ${ }^{11}$ highlights the importance of circulatory system disease as the most common cause of death, also mentioning respiratory system and digestive system disease.

To the best of our knowledge, this is the first study to investigate the risk of mortality following a severe fracture compared to a community control group among elderly people in a Brazilian sample. However, the study has certain weaknesses. Firstly, the sample size was not very large and did not allow an investigation into the mortality pattern of the two groups according to gender. Some studies have suggested that, irrespective of age, men face

\section{Resumo}

Fraturas decorrentes de queda entre idosos são um importante problema de saúde pública. Fraturas graves têm sido associadas com o maior risco de morte. Para investigar o perfil de mortalidade de idosos que sofreram fraturas graves, 250 indivíduos com 60 anos ou mais, hospitalizados devido à fratura decorrente de queda, e 250 idosos da população foram acompanhados por um ano. Esses grupos foram pareados por idade, sexo, momento da hospitalização do caso e vizinhança. Os óbitos foram identificados por meio do relacionamento probabilístico do banco de dados do estudo com a base de dados de mortalidade do estado. A mortalidade acumulada em um ano foi de $25,2 \%$ e $4 \%$ para idosos com e sem fratura grave, respectivamente. A distribuição dos óbitos não foi homogênea ao longo do tempo de seguimento. Dois terços das mortes entre paciente ocorreram no 1o trimestre após a fratura, enquanto que entre os controles os óbitos foram mais tardios. Doença cardíaca, pneumonia, sangramento digestivo, septicemia, embolia pulmonar, diabetes $e$ AVE foram causas importantes de morte no ano que se seguiu à fratura.

Fraturas Ósseas; Acidentes por Quedas; Idoso; Análise de Sobrevida; Mortalidade a greater excess risk of death after fracture than women 4,10 . Secondly, the quality of the information provided on cause of death was poor. For example, the sequence of events leading to death was not consistent. In some death certificates fall and/or fracture appeared as an intermediate cause in the sequence of fatal events.

\section{Final remarks}

In Brazil, as in many countries, the population is ageing fast. This trend is expected to lead to an increase in the incidence of severe fall-related fractures and consequent hospitalization. Since severe fractures increase the risk of death in those aged 60 years and over, interventions aimed at reducing falls in this group are urgently required. With regard to post-fracture care, the fact that almost half of deaths among the elderly with severe fractures occur during the first month after the accident, and that two-thirds occur by the end of the first three month period after the incident, must be taken into account when defining interventions aimed at reducing mortality following hospitalization due to fracture.

\section{Contributors}

All authors made substantial contributions to the collection, analysis and interpretation of data. E. S. F. Coutinho performed the survival analysis and wrote the first draft of the manuscript. K. V. Bloch carried out the analysis of the cause of deaths and critically revised the content of the drafts of the manuscript up to the final (submitted) version. C. M. Coeli was responsible for the datasets linkage process and critically reviewed the content up to the final (submitted) version.

\section{Acknowledgments}

We are grateful to the Wellcome Trust for providing funding for the fieldwork (data collection), equipment, and travel costs and to CNPq for providing scholarships, materials, and supplies. E. S. F. Coutinho, K. V. Bloch, C. M. Coeli were partially supported by the CNPq. 


\section{References}

1. Francis RM. Falls and fractures. Age Ageing 2001; 30 Suppl 4:25-8.

2. Masud T, Morris RO. Epidemiology of falls. Age Ageing 2001; 30 Suppl 4:3-7.

3. Hartholt KA, Oudshoorn C, Zielinski SM, Burgers PTBW, Panneman MJM, van Beeck EF, et al. The epidemic of hip fractures: are we on the right track? PLoS ONE 2011; 6:e22227.

4. Abrahamsen B, van Staa T, Ariely R, Olson M, Cooper C. Excess mortality following hip fracture: a systematic epidemiological review. Osteoporos Int 2009; 20:1633-50.

5. Coutinho ESF, Bloch KV, Rodrigues LC. Characteristics and circumstances of falls leading to severe fractures in elderly people in Rio de Janeiro, Brazil. Cad Saúde Pública 2009; 25:455-9.

6. Coutinho ESF, Fletcher A, Bloch KV, Rodrigues LC. Risk factors for falls with severe fracture in elderly people living in a middle-income country: a case control study. BMC Geriatrics 2008, 8:21.

7. Camargo Jr. KR, Coeli CM. Reclink: aplicativo para o relacionamento de bases de dados, implementando o método probabilistic record linkage. Cad Saúde Pública 2000; 16:439-47.
8. Coutinho ESF, Coeli CM. Acurácia da metodologia de relacionamento probabilístico de registros para identificação de óbitos em estudos de sobrevida. Cad Saúde Pública 2006; 22:2249-52.

9. Haentjens P, Magaziner J, Colón-Emeric CS, Vanderschueren D, Milisen K, Velkeniers B, et al. Meta-analysis: excess mortality after hip fracture among older women and men. Ann Intern Med 2010; 152:380-90.

10. Roche JJW, Wenn RT, Sahota O, Moran CG. Effect of comorbidities and postoperative complications on mortality after hip fracture in elderly people: prospective observational cohort study. BMJ 2005; 331:1374

11. Panula J, Pihlajamäki H, Mattila VM, Jaatinen P, Vahlberg T, Aarnio P, et al. Mortality and cause of death in hip fracture patients aged 65 or older: a population-based study. BMC Musculoskelet Disord 2011; 12:105.

Submitted on 15/Aug/2011

Approved on 26/Jan/2012 